\title{
Trends and ethnic differences in hospital admissions and mortality for congestive heart failure in the elderly in Singapore, 1991 to 1998
}

\author{
T P Ng, M Niti
}

Heart 2003;89:865-870

See end of article for authors' affiliations

Correspondence to

Associate Professor Tze Pin

$\mathrm{Ng}$, Departments of

Psychological

Medicine/Community,

Occupational and Family

Medicine, National

University of Singapore,

16 Medical Drive,

Singapore 117595;

cofngtp@nus.edu.sg

Accepted

27 February 2003
Objectives: To describe trends in hospital admissions and mortality from congestive heart failure in the elderly population aged 65 years and over in Singapore, 1991 to 1998.

Design: Analysis of trends and population subgroup differences in rates of hospital admission and mortality for a primary diagnosis of congestive heart failure, classified as ICD-9, codes 428, 402.0, 402.11, and 402.91.

Setting: The state of Singapore (multiethnic population of three million: Chinese $77 \%$, Malay 14\%, Indian 8\%).

Results: Congestive heart failure accounted for $4.5 \%$ of all hospital admissions and $2.5 \%$ of overall mortality in this age group. Age adjusted hospital admission rates for congestive heart failure increased by $38 \%$ (from 85.4 per 10000 in 1991 to 110.3 per 10000 in 1998), while mortality decreased by $20 \%$ (from 7.3 per 10000 in 1991 to 6.1 per 10000 in 1998). The decline in mortality was greater in women than in men. There were no sex differences in the rates of hospital admission, but there were significant ethnic differences in admissions and mortality. Thus hospital admissions for congestive heart failure were about 35\% higher in both Malays and Indians than in Chinese; and mortality was 3.5 times higher in Malays, but was about the same in Indians and Chinese. Over the period studied, mortality from congestive heart failure declined in both Chinese and Indians, but rose in Malays. The increases in hospital admissions were similar in both sexes and all ethnic groups.

Conclusions: An increasing rate of hospital admission accompanied by declining mortality from congestive heart failure is occurring in elderly people in this Asian multiethnic population. However, there are pronounced ethnic differences, with both Malays and Indians showing higher hospital admission rates than Chinese, and Malays showing a rising mortality as opposed to the falling mortality in the other ethnic groups.

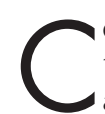
ongestive heart failure is a leading cause of admission to hospital among elderly people. ${ }^{1-3}$ It is estimated that about $75 \%$ of the cost of care for patients with congestive heart failure is spent on hospital admissions. ${ }^{4}$ The burden on the hospital care system will increase with the growth of the elderly population and the rising prevalence and incidence of congestive heart failure in elderly people. Improvements in survival from cardiovascular disease are related to the use of effective pharmacological treatments such as angiotensin converting enzyme inhibitors, $\beta$ blockers, and thrombolytic agents along with angioplasty and coronary artery bypass surgery to tackle ischaemic heart disease and hypertension. However, improved survival of patients with these underlying cardiovascular disorders will lead to an increase in the numbers of people who are vulnerable to the subsequent development of congestive heart failure.

Increases in age adjusted rates of hospital admission for congestive heart failure have been reported in recent years in the USA, ${ }^{56}$ Scotland, ${ }^{78}$ the Netherlands, ${ }^{9}$ Spain, ${ }^{3}$ and Canada. ${ }^{12}$ Outside North America and Europe, population based information on trends in congestive heart failure is scanty, especially in Asian populations living in rapidly developing countries in the East. Among these, the multiethnic population of Singapore (77\% Chinese, 14\% Malay, $8 \%$ Indian) has undergone a significant demographic and epidemiological transition, such that cardiovascular diseases are now the principal causes of hospital admission among the rapidly growing proportion of elderly people (at present $8 \%$ of the population, and expected to reach $20 \%$ by the year 2030). Population based data provide important information for evaluating the burden of congestive heart failure and the performance and effectiveness of hospital care. There are few reports of ethnic differences in rates and trends of congestive heart failure.

In this paper we describe recent trends and examine ethnic and sex differences in hospital admission and mortality from congestive heart failure in the elderly population aged 65 years and over in Singapore during the period 1991 to 1998.

\section{METHODS}

\section{Definitions}

For the purposes of the study, congestive heart failure was defined using only primary diagnoses of the following rubrics of the ninth revision of the International classification of diseases (ICD-9): "heart failure" (ICD-9 code 428) and "hypertensive heart disease with heart failure" (402.0, 402.11, and 402.91). The number of hospital admissions under the rubric 402 was small, constituting about $2 \%$ of total "heart failure" admissions.

Ethnic classification was based on the standard methodology employed by the Office for Singapore Population Census, and refers to a person's "ethnicity," as declared by the respondent. For persons of mixed parentage, they are usually declared under the declared ethnicity of their fathers. In Singapore, "Chinese" ethnicity refers to persons of Chinese origin, and comprises various dialect groups such as Hokkiens, Teochews, and Cantonese in the majority, and others such as Hakkas, Hainanese, Hockchias, Foochows, Henghuas, Shanghainese, and so on. "Malay" ethnicity refers to persons of Malay or Indonesian origin, such as Javanese, 
Table 1 Hospital admissions and mortality from congestive heart failure in elderly people ( $\geqslant 65$ years) by demographic characteristics, 1991-98

\begin{tabular}{|c|c|c|c|c|}
\hline \multirow[b]{2}{*}{ Characteristic } & \multicolumn{2}{|c|}{ Admissions } & \multicolumn{2}{|c|}{ Mortality } \\
\hline & $\mathrm{n}$ & $\%$ & $\mathrm{n}$ & $\%$ \\
\hline Total & $15774^{*}$ & & $1064 \dagger$ & \\
\hline \multicolumn{5}{|l|}{ Sex } \\
\hline Female & 8425 & 53.4 & 638 & 60.0 \\
\hline Male & 7349 & 46.6 & 426 & 40.0 \\
\hline \multicolumn{5}{|c|}{ Age group (years) } \\
\hline $65-69$ & 3732 & 23.6 & 95 & 9.0 \\
\hline 70-74 & 3974 & 25.2 & 180 & 16.9 \\
\hline $75-79$ & 3300 & 20.9 & 243 & 22.8 \\
\hline $80+$ & 4768 & 30.3 & 546 & 51.3 \\
\hline \multicolumn{5}{|l|}{ Ethnicity } \\
\hline Chinese & 12088 & 76.6 & 698 & 65.6 \\
\hline Indian & 1547 & 9.8 & 52 & 4.9 \\
\hline Malay & 2139 & 13.6 & 314 & 29.5 \\
\hline \multicolumn{5}{|l|}{ Period } \\
\hline 1991 & 1436 & 9.1 & 122 & 11.5 \\
\hline 1992 & 1464 & 9.3 & 121 & 11.4 \\
\hline 1993 & 1710 & 10.8 & 145 & 13.6 \\
\hline 1994 & 1825 & 11.6 & 129 & 12.1 \\
\hline 1995 & 2086 & 13.2 & 159 & 14.9 \\
\hline 1996 & 2483 & 15.7 & 134 & 12.6 \\
\hline 1997 & 2313 & 14.7 & 119 & 11.2 \\
\hline 1998 & 2457 & 15.6 & 135 & 12.7 \\
\hline
\end{tabular}

*Admissions for congestive heart failure accounted for $4.5 \%$ of total admissions.

†Deaths from congestive heart failure accounted for $2.5 \%$ of total deaths.

Boyanese, and Bugis. "Indian" ethnicity refers to persons of Indian, Pakistani, Bangladeshi , and Sri Lankan origin such as Tamils, Malayalis, Punjabis, Bengalis, and Singhalese. All persons other than Chinese, Malays, and Indians-which includes Eurasians, Europeans, Arabs, Japanese, and so on-are classified under "other". In this study, it is recognised that "ethnicity" is not equated with race, but represents a complex construct of biology, culture, language, religion, and, pertinently in this study, distinct health beliefs and health behaviours.

\section{Data source}

The data for the study were analysed using two independent population based data sources. We obtained hospital admission data from the national administrative database of the Central Claims Processing System (CCPS) in the Ministry of
Health, which began operation in 1991 to facilitate claims for hospital charges from all hospitals in Singapore (government owned restructured hospitals and private hospitals). As the CCPS captures management information for all hospital admission episodes in the country, this administrative data source provides population based data that are complete and representative for the total population of patients admitted for congestive heart failure. The information in the database includes essential personal data and medical diagnoses. All diagnoses at discharge were routinely coded by trained medically qualified medical coders using the International classification of disease-clinical modification (ICD-9 CM, ICD-10CM). Aggregated data on annual numbers of hospital admissions for congestive heart failure were obtained for each year for the period from 1991 to 1999, separately for each sex and ethnic group, and in five year age groupings for elderly patients aged 65 years and over. Hospital admission data were not disaggregated for individual patients to distinguish first admissions from readmissions; hence readmissions for the same patient were counted as separate events.

Population based mortality data for congestive heart failure using identical ICD-9 codes were obtained separately from the Department of Statistics for the same period from 1991 to 1999 from the National Registration Department. The data were similarly aggregated by individual calendar year, sex, and ethnicity (Chinese, Malays, and Indians), and five year age groupings for elderly patients aged 65 years and over. It should be noted, therefore, that the mortality rates in the study do not refer to individual patient linked case fatality rates, and comprises both in-hospital and out of hospital mortality from congestive heart failure.

Hospital admissions and mortality from congestive heart failure were calculated using mid-year population estimates for sex, ethnicity, and five year age groups provided by the Department of Statistics. Rates were age standardised by the direct method, using the 1991 population as standard. Percentage changes in congestive heart failure admissions and mortality were calculated using regression techniques. The rates for hospital admission and mortality were both expressed as numbers per 10000 persons. Rate ratios and 95\% confidence intervals - adjusted for sex, age, ethnicity, and calendar year-were calculated by Poisson regression modelling techniques using the GENMOD procedure in the SAS package of statistical programs.

\section{RESULTS}

\section{Hospital admission}

For the period from 1991 to 1998, among elderly persons aged 65 years and over there were 15774 hospital admissions for congestive heart failure (accounting for $4.5 \%$ of all admissions) (table 1). The number of admissions for congestive

Table 2 Percentage changes in hospital admissions and mortality $†$ in elderly people (aged $\geqslant 65$ years), 1991-98

\begin{tabular}{|c|c|c|c|c|c|c|}
\hline & \multicolumn{3}{|c|}{ Admission rate/10000 population } & \multicolumn{3}{|c|}{ Mortality/10000 population } \\
\hline & 1991 & 1998 & $\%$ Change & 1991 & 1998 & $\%$ Change \\
\hline Overall & 85.4 & 110.3 & $+38.4^{* *}$ & 7.3 & 6.1 & $-19.8^{*}$ \\
\hline \multicolumn{7}{|l|}{ Sex } \\
\hline Female & 79.4 & 108.7 & +43.8 ** & 8.4 & 6.6 & $-25.7^{*}$ \\
\hline Male & 92.6 & 112.2 & $+32.5^{* *}$ & 5.8 & 5.4 & -9.9 \\
\hline \multicolumn{7}{|l|}{ Ethnicity } \\
\hline Chinese & 79.7 & 102.3 & $+37.9 * *$ & 6.1 & 4.4 & $-36.3^{*}$ \\
\hline Indian & 118.8 & 141.8 & $+47.4^{* *}$ & 8.6 & 2.2 & $-70.5^{*}$ \\
\hline Malay & 85.4 & 147.1 & $+30.0 * * *$ & 15.6 & 21.4 & +54.3 व \\
\hline
\end{tabular}


Table 3 Hospital admissions and mortality rates $\dagger$ and rate ratios in the elderly people (aged $\geqslant 65$ years), 1991-98

\begin{tabular}{lllll}
\hline Characteristic & $\begin{array}{l}\text { Admission rate/ } \\
10000 \text { population }\end{array}$ & $\begin{array}{l}\text { Rate ratio } \\
(95 \% \mathrm{Cl})\end{array}$ & $\begin{array}{l}\text { Mortality rate/ } \\
10000 \text { population }\end{array}$ & $\begin{array}{l}\text { Rate ratio } \\
(95 \% \mathrm{Cl})\end{array}$ \\
\hline $\begin{array}{l}\text { Overall } \\
\text { Sex }\end{array}$ & 101.0 & & 6.8 & \\
$\quad$ Female & 98.2 & 1.00 & 7.4 & 1.00 \\
$\quad \begin{array}{l}\text { Male } \\
\text { Ethnicity }\end{array}$ & 104.3 & $1.02(0.94$ to 1.12$)$ & 6.0 & $0.78(0.55$ to 1.10$)$ \\
$\quad$ Chinese & 94.8 & 1.00 & 5.5 & 1.00 \\
$\quad \begin{array}{ll}\text { Indian } \\
\text { Malay }\end{array}$ & 129.1 & $1.35(1.16 \text { to } 1.57)^{* * *}$ & 4.3 & $0.92(0.42$ to 1.99$)$ \\
\hline
\end{tabular}

†Age standardised rates per 10000 population.

$* * * p<0.001$

$\mathrm{Cl}$, confidence interval.
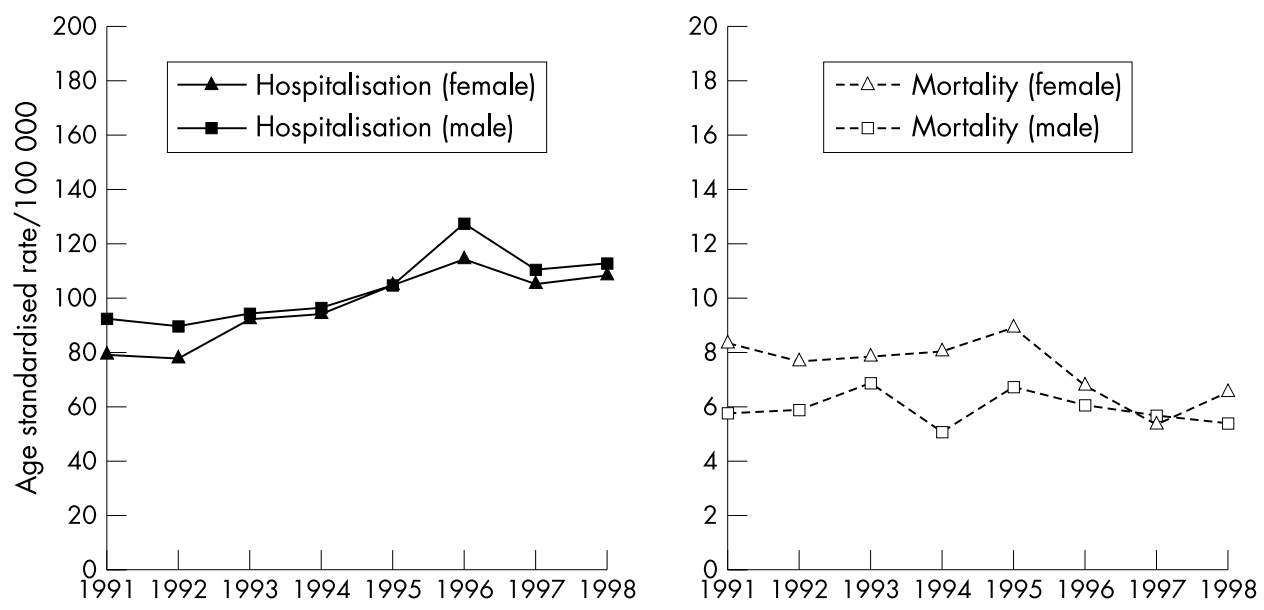

Figure 1 Trends in hospital admissions and mortality from congestive heart failure (age standardised) in elderly people $(\geqslant 65$ years) by sex, Singapore, 1991 to 1998.
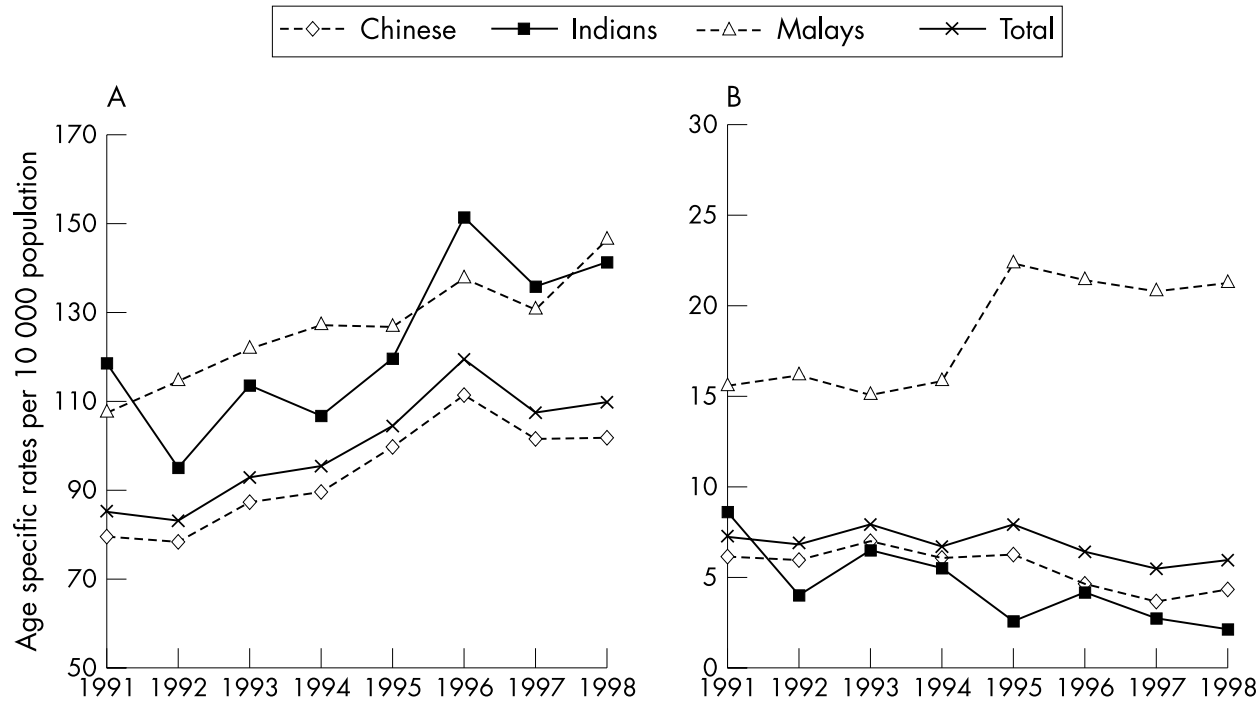

heart failure rose from 1436 in 1991 to 2457 in 1998, an absolute increase of $71 \%$. The age standardised hospital admission rates for congestive heart failure showed an increase of $38 \%$, from 85.4 per 10000 in 1991 to 110.3 per 10000 in 1998 $(p<0.01)$ (table 2, fig 1). Admissions from this cause were not significantly greater in men than in women (table 3 ), but there were important differences among the three ethnic groups, with rates about $35 \%$ higher in both Indians and Malays than in Chinese. All sex and ethnic groups showed similar increases in rates of hospital admission for congestive heart failure during the period (fig 2).

\section{Mortality}

In all, there were 1064 deaths from congestive heart failure (2.5\% of deaths from all causes or $5.6 \%$ of all cardiovascular deaths). The yearly number of deaths from congestive heart failure rose by $11 \%$ from 122 in 1991 to 135 in 1998 (table 1). However, age standardised mortality showed a significant decrease of $20 \%(p<0.05)$, from 7.3 per 10000 in 1991 to 6.1 per 10000 in 1998 (table 2, fig 1). As with the hospital admission rates, the difference in mortality between men and women was not significant. Nevertheless, mortality in women showed a significant decline of $26 \%$, from 8.4 per 10000 in 1991 to 6.6 in 1998, whereas in men the decline in mortality was non-significant (from 5.8 per 10000 in 1991) (table 2, fig 1).

Ethnic differences in mortality were pronounced (table 3 ). Although Indians had higher rates of hospital admission for congestive heart failure than Chinese, the mortality was not significantly different. This was because Indians showed a steeper decline in mortality between 1991 and 1998 than the 
Chinese (table 2, fig 1). In 1991, the mortality among Indians was higher than among Chinese, $8.6 v 6.1$ per 10000 , but it declined substantially (by $70 \%$ ) to 2.2 per 10000 in 1998 , whereas the decline in the Chinese was only $36 \%$, to 4.4 per 10 000. In contrast, Malays not only had higher rates of hospital admission than Chinese, but their mortality was greatly increased (3.5 times that of the Chinese). Whereas both Chinese and Indians showed decreasing mortality from congestive heart failure, Malays had increasing mortality-up by $54 \%$ from 15.6 per 10000 in 1991 to 21.4 per 10000 in 1998.

\section{DISCUSSION}

The interpretation of our findings should take into account several limitations in the data used for the analyses. As hospital admissions rather than individuals were used as the unit of analysis, the readmission of the same person is counted as a separate event. In general, hospital admission rates at the individual patient level are $20-30 \%$ lower than those with hospital admission episodes as the unit of analysis. ${ }^{10}$ Analyses that distinguish rates of admission and readmission should give a better understanding of factors that play different roles in first admissions and readmissions for congestive heart failure. As only a principal diagnosis code for congestive heart failure was used, the analyses did not take this condition into account when it was coded as a secondary diagnosis. To the extent that physicians tended to focus investigation on the primary or precipitating cardiovascular cause of heart failure, heart failure per se is less often coded as a principal diagnosis leading to hospital admission. Similarly, mortality data did not include congestive heart failure as a contributing cause of death. Heart failure is five to six times more likely to be reported as a contributing factor than as the underlying cause of death on death certificates. ${ }^{11}{ }^{12}$ Thus the burden of congestive heart failure on the hospital care system is likely to be underestimated. Differences in the definition of congestive heart failure or the use of ICD rubrics make intercountry comparisons of hospital admissions and mortality difficult. In most countries, however, the vast majority (95\%) of patients admitted to hospital for heart failure fall under the rubric $428 .^{7}$

It is possible that the hospital admission data for congestive heart failure for 1991-92 and their lower figures reported could be an artefact of the introduction of a new database at that time. This may arguably result in overestimates of the changes during the period of 1991-98 for the total population. Upon reanalysis of the data after excluding hospital admissions in 1991 and 1992, we estimated the percentage changes from 1993 to 1998 at $21 \%$, which is still considerable. Given this, our results of the relative comparisons of the ethnic and sex differences remain essentially unchanged, as would be expected if the overestimates were randomly and equally distributed among them.

In addition, although the reported changes were based on regression estimates of trends over individual years, nevertheless some fluctuations in rates between individual years may not be random. A case in point is the sharp change in hospital admission rates between 1995 and 1997. However, we were unable to think of any plausible explanation for this.

Also, mortality and hospital admission data were obtained from two different sources, both of which are aggregated in nature. Thus the inferences drawn from the interpretation of the relation between hospital admission and mortality trends were indirect. We recognise that data on in-hospital case fatality would be more illuminating; however we do not have such nationwide data. It would be desirable to disaggregate hospital admission on the basis of index admissions and readmissions, so that it is possible to evaluate which ethnic group experienced the greatest proportion of readmissions following an index admission, what proportion of deaths by ethnic groups took place during and after the index hospital admission for congestive heart failure, and whether higher rates of mortality from congestive heart failure as observed among Malays are associated with death during the index visit or lower rates of hospital readmission.

\section{Trend analysis}

Increases in rates of hospital admission for congestive heart failure among the elderly have been reported in various developed countries. ${ }^{1-7}$ However, there have been no previous reports of this observation in rapidly developing countries from the East. Also, few reports have involved observations on concurrent trends in both hospital admissions and mortality from congestive heart failure to evaluate the burden on hospital services as well as their performance and outcomes.

Increases in hospital admission for congestive heart failure have also been observed in the Netherlands, ${ }^{9}$ the USA, ${ }^{3-5}$ and Scotland. ${ }^{78}$ Readmissions are a prominent feature of patients with congestive heart failure. ${ }^{367}$ In the Netherlands, $14 \%$ of patients with congestive heart failure were readmitted within six months after their first discharge, ${ }^{9}$ while in the USA ${ }^{45}$ and Scotland, ${ }^{7}$ the readmission rates among hospital survivors were $21 \%$ and $23 \%$, respectively. In Scotland, ${ }^{7}$ it is estimated that $83 \%$ of the patients with readmissions for congestive heart failure as the principal diagnosis require one readmission, $13 \%$ require two, and $3 \%$ require three readmissions within the year. Increases in hospital inpatient care for congestive heart failure might reflect increases in readmissions and be a reflection of the general quality of care at both the primary and the hospital level. However, this is generally thought not to be a principal explanation. ${ }^{7}$

Rising trends in hospital admissions for congestive heart failure may also be explained by a greater prevalence of the condition or by hospital admission at an earlier stage in the disease. A real increase in (first episode) admissions for congestive heart failure could reflect an increasing prevalence of the condition, owing to improved survival from its underlying causes. Indeed, published data of the Singapore myocardial infarction registry between 1988 and 1997 (table 4) provided evidence of decreasing post-admission case fatality rates in patients with myocardial infarction. It is likely that the numbers and rate of hospital admissions for congestive heart failure will continue to increase with increasing survival after myocardial infarction, with a higher incidence and prevalence of congestive heart failure, and with the progressive aging of the population. Patients with congestive heart failure may also be admitted at an earlier stage of the disorder, because of earlier and better recognition of heart failure thanks to the increasing use of more accurate and comprehensive diagnostic procedures, such as echocardiography, to confirm the diagnosis.

In this study, other possible explanations to be considered for increased admissions include changing hospital admission and discharge policies, and changing patterns of expectations and demands for care associated with nationwide restructuring of hospital care financing and delivery in recent years. However, diagnostic related group (DRG) classification came into place in Singapore only in 2001, and hence this ruled out the possibility of adverse DRG effects of premature discharges with subsequent higher rates of readmission.

Our results showing falling mortality in the face of increasing hospital admissions are similar to those observed in Spain, ${ }^{2}$ where increases in admissions for congestive heart failure and accompanying declines in mortality were observed for the period from 1980 to 1993. This may suggest improved in-hospital management of congestive heart failure. In Canada, ${ }^{1}$ a decline in age adjusted mortality from congestive heart failure was also observed in the period from 1980 to 1989. From 1990 to 1997, congestive heart failure (with ICD 428 as the sole primary diagnosis) among elderly people in 
Table 4 Rates (age standardised) of antecedent conditions for congestive heart failure in adult Singaporeans

\begin{tabular}{|c|c|c|c|c|c|c|c|c|c|}
\hline & & \multicolumn{4}{|l|}{ Rates } & \multicolumn{4}{|c|}{ Per cent change } \\
\hline & & All & Chinese & Indian & Malay & All & Chinese & Indian & Malay \\
\hline Diabetes mellitus, prevalence per $100000^{*}$ & $\begin{array}{l}1992 \\
1998\end{array}$ & $\begin{array}{l}8.4 \\
8.1\end{array}$ & $\begin{array}{l}7.7 \\
7.0\end{array}$ & $\begin{array}{l}12.2 \\
14.5\end{array}$ & $\begin{array}{l}10.1 \\
10.7\end{array}$ & -3.6 & -9.1 & +18.8 & +5.9 \\
\hline Hypertension, prevalence per $100000^{*}$ & $\begin{array}{l}1992 \\
1998\end{array}$ & $\begin{array}{l}22.5 \\
26.6\end{array}$ & $\begin{array}{l}22.3 \\
26.0\end{array}$ & $\begin{array}{l}20.3 \\
23.7\end{array}$ & $\begin{array}{l}24.7 \\
32.3\end{array}$ & +18.2 & +16.6 & +16.7 & +30.8 \\
\hline $\begin{array}{l}\text { AMl, incidence per } 100000 \\
(30-64 \text { years }) \dagger\end{array}$ & $\begin{array}{l}1991 \\
1999\end{array}$ & $\begin{array}{r}105.9 \\
93.0\end{array}$ & $\begin{array}{l}85.3 \\
71.3\end{array}$ & $\begin{array}{l}247.2 \\
241.0\end{array}$ & $\begin{array}{l}185.4 \\
164.6\end{array}$ & -15.0 & -14.9 & -14.5 & -5.3 \\
\hline $\begin{array}{l}\text { Case fatality (one year post-AMI) per } 100 \text { patients } \\
\text { (20-64 years) } \ddagger\end{array}$ & $\begin{array}{l}1988 \\
1997\end{array}$ & $\begin{array}{l}31.3 \\
25.1\end{array}$ & $\begin{array}{l}29.0 \\
25.3\end{array}$ & $\begin{array}{l}28.5 \\
21.8\end{array}$ & $\begin{array}{l}40.6 \\
27.4\end{array}$ & -22.6 & -20.5 & -21.5 & -29.4 \\
\hline
\end{tabular}

Sources:

*National Health Survey, Singapore.

†Singapore myocardial infarct registry data, published data: population 30-64 years.

fUnpublished data based on National Heart Centre and Singapore myocardial infarct registry data.

Percentage changes were calculated as proportions of change from baseline in 1992 for prevalence data, and from regression estimates based on consecutive years for year of incidence data from 1991 to 1998 . AMI, acute myocardial infarction.

Montreal $^{2}$ showed a significant increase among hospital admissions, whereas mortality did not change significantly. These results were taken to suggest that "the management of congestive heart failure and its antecedents has improved in recent years". We do not have relevant data to show the effectiveness of in-hospital care for heart failure in Singapore. Previous studies have shown that between $7-15 \%$ of all patients with a principal discharge diagnosis of congestive heart failure die during their index hospital admission. ${ }^{613}$ Direct evidence of improved prognosis in the in-hospital treatment of heart failure in the USA, ${ }^{46}$ the Netherlands, ${ }^{9}$ and Scotland ${ }^{7}$ has been shown in the downward trends in case fatality in hospital inpatients with congestive heart failure, despite significant increases in the trend of congestive heart failure severity. ${ }^{4}$

\section{Sex differences}

No sex differences in overall hospital admissions or mortality were observed in this study. However, women appear to have experienced a somewhat greater increase in hospital admission and a greater decline in mortality than men. In contrast, in Spain women had a greater increase in hospital admission but a lower decline in mortality than men. ${ }^{3}$ It is uncertain whether the treatment of congestive heart failure is more effective in women, as sex differences and changes in clinical profile are also likely to explain these observations. The Framingham heart study ${ }^{14}$ showed that women have a better prognosis than men, though women are more likely to stay longer in hospital. ${ }^{3}$ The limitation inherent in our hospital discharge data did not allow us to examine sex differences in readmission rates and clinical profiles determining differences in mortality risk. Women with congestive heart failure are on average older than men. ${ }^{6}{ }^{14}$ Coronary artery disease is the most common underlying cause of congestive heart failure in men, while in women, hypertension, diabetes, and atrial fibrillation are more common causes. ${ }^{14}$ Women with coronary heart disease are also more likely to have preserved left ventricular systolic function, despite being treated differently from men. Data from the Singapore myocardial infarction register showed that case fatality after hospital admission of patients with acute myocardial infarction declined faster in women than in men between 1988 and 1997 (unpublished data).

\section{Ethnic differences}

Few studies have investigated the causes of ethnic variation in hospital admission and mortality from congestive heart failure. ${ }^{10} 13$ Ethnic differences are variously attributed to differences in underlying pathophysiology, the type and number of co-morbidities, the clinical severity (measured by the left ventricular ejection fraction), therapeutic compliance, frequency of diagnostic and therapeutic interventions, and responsiveness or tolerance to treatment. ${ }^{15}$ In the USA, ${ }^{10}{ }^{13}$ African Americans are reported to be more likely to be readmitted, to have a longer period in hospital, to have higher hospital costs (reflecting more complex and difficult to treat conditions), and to be less likely to be treated by cardiologists, thus suggesting worse access and quality of care.

Data on co-morbidity and other clinical data are lacking in the CCPS hospital admission database. Nevertheless, we are able to make indirect inferences on the possible reasons of ethnic differences in congestive heart failure observed in this study. Data from the Singapore national health surveys (1992 and 1998) ${ }^{16}{ }^{17}$ suggest that, compared with the Chinese, the Malays and Indians have higher rates of diabetes and hypertension (table 4), and that the proportion of poorly controlled diabetes and hypertension in Malays, in particular, is greater. Data from the Singapore myocardial infarction registry also show that both Indians and Malays (compared with the Chinese) have a higher incidence of myocardial infarction (table 4). It is interesting that case fatality after myocardial infarction was especially high in Malays, but this has fallen steeply over the past decade, although it still remained higher in 1999 than in the other ethnic groups. Taken together, these data suggest that whereas Indians and Malays both have a higher risk of cardiovascular disease, treatment of these antecedent conditions appears to meet with better results in Indians and poorer results in Malays. These observations parallel the pronounced decline in congestive heart failure mortality in Indians and the increase in mortality in Malays observed in this study. The ethnic groups differ in income and education. In particular, lower levels of income and education among Malays are important factors explaining inequities of access to and receipt of care. They are related to lower functional health literacy (manifested in such abilities as reading prescription labels, following testing instructions, and understanding treatment directions) and language barriers posing difficulties of communication between patient and their care providers.

\section{Conclusions}

Increasing rates of hospital admission accompanied by a declining mortality from congestive heart failure in the elderly were observed in an Asian multiethnic population. There were pronounced ethnic differences, with both Malays and Indians showing higher hospital admission rates than Chinese. In contrast to a declining mortality in Chinese and Indians, Malays showed rising mortality. 


\section{Authors' affiliations}

T P Ng, M Niti, Department of Community, Occupational and Family Medicine, National University of Singapore, Singapore

\section{REFERENCES}

Brophy JM. Epidemiology of congestive heart failure: Canadian data from 1970 to 1989. Can J Cardiol 1992;8:495-8.

2 Feldman DE, Thivierge C, Guerard L, et al. Changing trends in mortality and admissions to hospital for elderly patients with congestive heart failure in Montreal. Can Med Assoc J 2001;165:1033-6.

3 Rodriguez-Artalejo F, Guallar-Castillon P, Banegas Banegas JR, et al. Trends in hospitalization and mortality for heart failure in Spain, 1980-1993. Eur Heart J 1997:18:1771-9.

4 Polanczyk CA, Rohde LE, Dec GW, et al. Ten-year trends in hospital care for congestive heart failure: improved outcomes and increased use of resources. Arch Intern Med 2000;160:325-32.

5 Ghali JK, Cooper R, Ford E. Trends in hospitalization rate for heart failure in the United States, 1973-1986. Arch Intern Med 1990;150:769-73.

6 MacIntyre K, Capewell S, Stewart S, et al. Evidence of improving prognosis in heart failure: trends in case fatality in 66547 patients hospitalized between 1986 and 1995. Circulation 2000;102:1126-31.

7 McMurray J, McDonaugh T, Morrison CE, et al. Trends in hospitalization for heart failure in Scotland 1980-1990. Eur Heart J 1993; 14:1158-62.
8 Stewart S, Maclntryre K, MacLeod MMC, et al. Trends in hospitalization for heart failure in Scotland, 1990-1996: an epidemic that has reached its peak? Eur Heart J 2001;22:209-17.

9 Reitsma JB, Mosterd A, de Craen AJ, et al. Increase in hospital admission rates for heart failure in the Netherlands, 1980-1993. Heart 1996;76:388-92.

10 Alexander M, Grumbach K, Remy L, et al. Congestive heart failure hospitalizations and survival in California: patterns according to race/ethnicity. Am HeartJ 1999;137:919-27.

11 Centers for Disease Control and Prevention. Changes in mortality from heart failure - United States, 1980-1995. JAMA 1998;280:874-5.

12 Gillum RF. Epidemiology of heart failure in the United States. Am Heart J 1993:126:1042-7.

13 Philbin EF, DiSalvo TG. Influence of race and gender on care process, resource use, and hospital-based outcomes in congestive heart failure. Am J Cardiol 1998:82:76-81.

14 Ho KKL, Andersen KM, Kannel WB, et al. Survival after the onset of congestive heart failure in Framingham Heart Study subjects. Circulation 1993;88:107-15.

15 Konstam MA. Progress in heart failure management? Lessons from the real world [editorial]. Circulation 2000;102:1076-8.

16 Ministry of Health. National Health Survey 1992. Singapore: $\mathrm{MOH} /$ Singapore National Printers, 1993.

17 Ministry of Health. National Health Survey 1998. Singapore: $\mathrm{MOH} /$ Singapore National Printers, 1999.

\section{IMAGES IN CARDIOLOGY}

\section{Cardiogenic shock in a young woman revealing juvenile haemochromatosis}

$\mathrm{T}$ ypically, haemochromatosis becomes symptomatic in women in post-menopausal life. Herein, we report an unusual presentation of haemochromatosis with refractory cardiogenic shock.

A 26 year old pregnant woman was admitted for congestive heart failure and rapid atrial fibrillation. She suffered from an unexplored hypogonadotrophic hypogonadism, and the pregnancy was induced by gonadotrophin therapy. Echocardiography showed a severe left ventricular dysfunction (ejection fraction $<20 \%$ ) without increased left ventricular end diastolic diameter nor septal hypertrophy. The diagnosis of fulminant myocarditis was first suspected. Three days after the admission, she presented a cardiogenic shock refractory to inotropic agents, requiring urgent surgical mechanical circulatory support. The resected left ventricular apex showed no evidence of myocarditis but revealed a major iron overload in all the cardiac myocytes observed with Pearls' stain (right). The diagnosis of haemochromatosis was confirmed in serum by the increase in transferrin saturation and in ferritin concentration. Genetic study, performed in the leucocytes' DNA of the patient, did not find the mutations C282Y and H63D of the HFEl gene.

The patient had two sisters from a consanguineous family. One of the sisters suffers from hypogonadotrophic hypogonadism as well, and haemochromatosis was confirmed by abnormal biochemical iron parameters. These clinical and familial data strongly suggest that our patient suffered from a juvenile form of haemochromatosis. The peculiarity of this

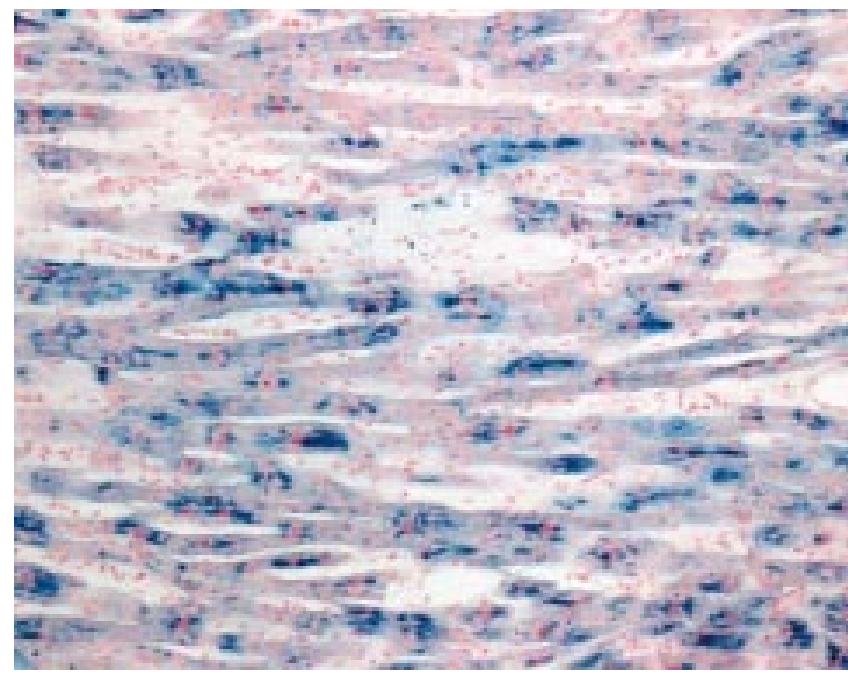

case is the extreme swiftness of the cardiac manifestation, looking like severe myocarditis. It is emphasised that unexplained cardiogenic shock or severe heart failure in young patients should evoke the diagnosis of juvenile haemochromatosis.

E Durand

$J$ M Grindo

P Bruneval

eric.durand@egp.ap-hop-paris.fr 